\title{
Finite ELEMENT MOdELling OF COLD DRAWING INNER FINNED TUBE
}

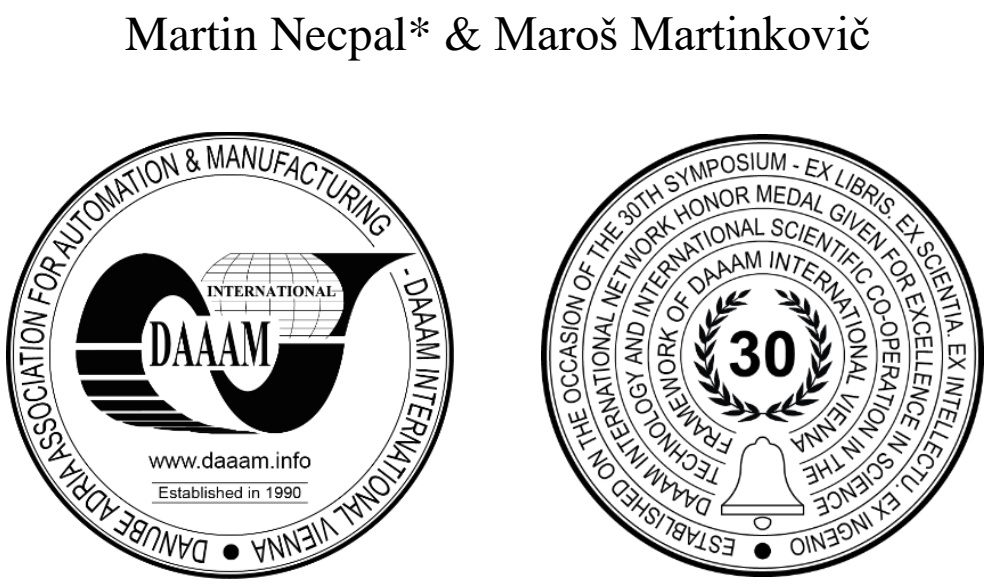

This Publication has to be referred as: Necpal, M[artin] \& Martinkovic, M[aros] (2019). Finite Element Modelling of Cold Drawing Inner Finned Tube, Proceedings of the 30th DAAAM International Symposium, pp.0622-0627, B. Katalinic (Ed.), Published by DAAAM International, ISBN 978-3-902734-22-8, ISSN 1726-9679, Vienna, Austria DOI: $10.2507 / 30$ th.daaam.proceedings.085

\begin{abstract}
The cold forming method and the process of the die drawing tubes are ranked among frequently used methods of production. The aim of this paper is the research of using Finite Element Method for analyses of the cold drawing process to produce tubes with the contoured internal surface. This is the process of pulling the tube through a die using a fixed mandrel whose shape is designed to achieve the shape of the inner finned tube. Commercial software DEFORM 3D is used for numerical simulation. The size and shape of the forming tools are designed by following the real requirements of industrial production for the shape of the resulting tubes. The input parameter, such as the material model and the initial boundary conditions of the simulation, is determined based on previous real experiments and investigations. The result of the analysis is an assessment of the stress-strain process of the forming as well as the resulting tube in the individual cross-sections of the tube ribs. The result of the numerical simulation assists in the understanding of the technological processes of forming, defining the necessary plastic properties of the formed material as well as in the construction of the forming tools.
\end{abstract}

Keywords: FEM; Cold Drawing Technology; Inner Finned Tube; Cold forming

\section{Introduction}

Inner finned tube or inner grooved tube is a heat transfer pipe with fins formed on the inside. Inner finned tubes have a larger internal surface area compared to formal steel pipes with a circular cross-section. Finned tubes are used in applications involving the transfer of heat from a hotter fluid to a colder fluid through a tube wall. The rate at which heat transfer can occur depends on the surface area to which each fluid is exposed. By extending the surfaces of heat transfer tubes, the inner finned tube with longitudinal ribs increases the efficiency of heat transferring performance. Basic two different tube drawing methods exist [1]. To produce an inner finned tube is possible to use only a mandrel drawing method using mandrel with ribs on surfaces. Depending on the dimension and shape of the mandrel, the internal grove of the tube depends. It is very important to fulfilling all geometrical requirements of the inner fined tube. Proper cold formability of the material is also very important to filling inner ribs of the tube [2].

By numerical simulation it is possible to optimize the forming process, to see the material flow a better understanding of the drawing process. In the world, there are some research works where the numerical finite methods are used to optimize the cold drawing process. A numerical model that predicts the final dimensions of the tube with very high accuracy in medical devices, like stents, cardiac valves, and implants, are described here [3]. In some studies [4], 
experimental results were compared with numerical simulation results. As hardware performance options and computing capabilities continue to grow, numerical simulation capabilities are also expanding. The macro-micro coupling finite element method to investigate the inner surface roughness evolution of AA6061 rectangular tube in the cold drawing process was used in research [5]. The micro-scale finite element model with initial surface roughness and reasonable model size was created firstly. Then the micro-scale finite element analysis (FEA) of surface roughness evolution was conducted based on the macro-scale analysis of the tube drawing process. Cold drawing of inner finned tubes and multirifled tubes is quite a new technology. Experiment approaches to investigate process parameters are very expensive in industrial conditions. Numerical simulation is almost always used in these processes for finding proper feedstock dimensions and tool geometry [6]. Another work [7] shows the importance to maintain the optimal position of the multi rifled plug concerning the drawing die. A variety of commercial software is available to simulate forming processes. Frequently used FEM software for various forming problems is DEFORM 3D [8].

The main goal of this article was to develop a suitable numerical model of cold drawing inner fined tube using commercial software DEFORM 3D and analyze the stress-strain state of the process and final tube in crossectional viewing.

\section{Formulation of the Finite Element Model}

DEFORM 3D and Lagrangian calculation has been set for numerical simulation of cold drawing technology. The initial simulation setup is illustrated in Fig 1. The position of the mandrel concerning the die was so the plug face flushes the end of the bearing length.

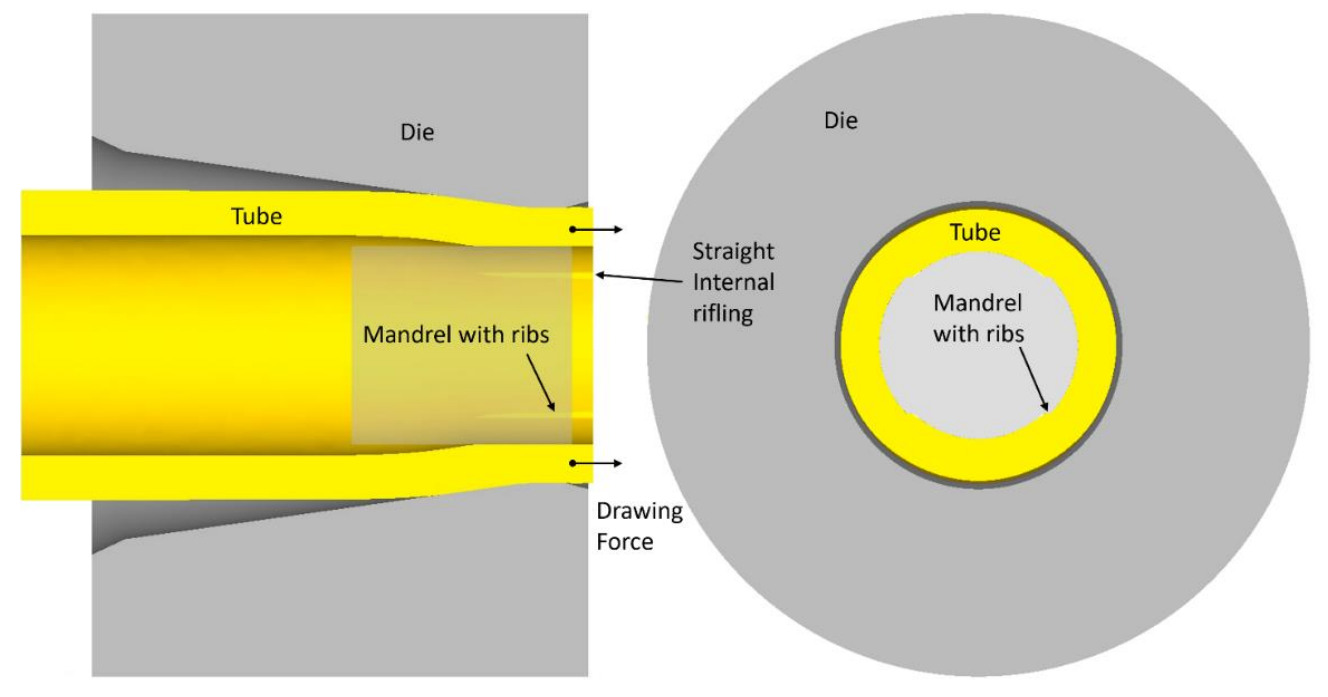

Fig. 1. Initial simulation setup

\subsection{Geometry}

The 3D model of the mandrel and die has been used. The simulation was simplified using the mirroring function, and a quarter of the cross-section of the pipe was used. The dimension of the drawing tube is diameter D $28 \mathrm{~mm}$ and wall thickness Wt of $4 \mathrm{~mm}$. Die approach angle is $8^{\circ}$ and the final diameter is $25 \mathrm{~mm}$. The calibration length of die $\mathrm{c}$ is $4 \mathrm{~mm}$. The mandrel cross-sectional shape and dimensions are shown in Fig 2.

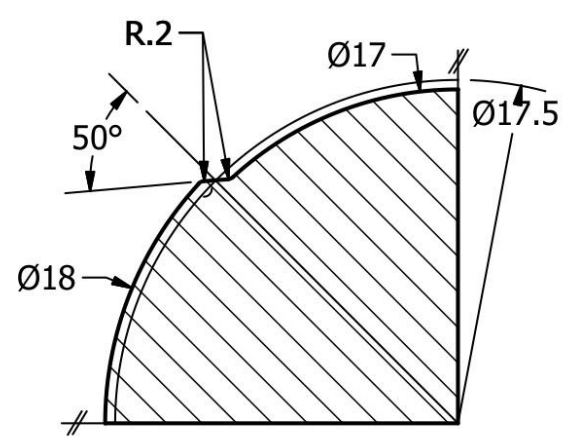

Fig. 2. Mandrel cross-sectional shape and dimensions 


\subsection{Materials}

The tube material was considered as plastic, the hardening is assumed as isotropic, and yield function type is set as Von Mises. As the temperature stays lower in cold drawing, the forming material properties do not vary and can, therefore, be supposed to be independent of the temperature variation. The relationship of material between true stress-strain for the FE was obtained by simple tensile strength test is given by [9]:

$$
\sigma=513 \bar{\varepsilon}^{0.44}+325[M P a]
$$

\subsection{Mesh}

The tube domain was filed by tetrahedron mesh. The size of the mesh is closely related to the accuracy and the number of mesh is related to the computation performance and calculation time. The tube domain was divided into subdomain for optimum meshing with the rib filling subdomain having the smallest elements.

As a rib area is a part of the high-stress domain with the smallest element length after every 50 steps the re-mesh procedure was implemented to continue the process and achieved the convergence. The cross section of the tube around rifling with visible mesh is illustrated in Fig. 3.

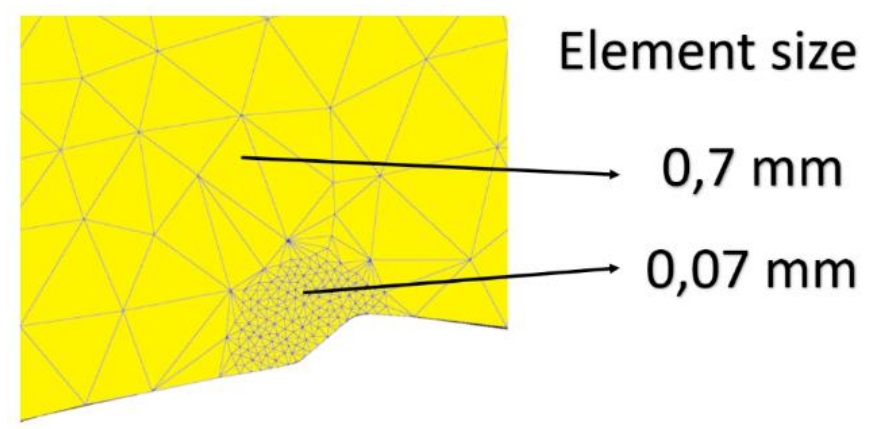

Fig. 3. Cross section of the tube with tetrahedral FEM mesh

\subsection{Boundary conditions}

The boundary condition that represents the constant speed of drawing is set to 9 m.min- 1 . The displacement conditions are applied to the mandrel and the die. A fixed condition is applied to one end of the tube. The real forming process is different. The tools are stationary objects and the tube is moving, but for numerical convergence, is better to set movable tools.

The friction coefficients between the tube and die and the tube and mandrel under lubricated condition are determined by inverse FE analyses. A linear dependence has been observed between the drawing force and the friction coefficient. The friction coefficient, which permits to match the simulated force with the measured one was set 0.05421 as follows [10].

\section{Result}

The Result after solving time approximately 40 minutes was evaluated in DEFORM-3D postprocessor. Some values were exported and for a clear display, it was necessary to use the plot function of MATLAB software.

\subsection{Evolution of the load}

For the proper design of forming tools as well as mandrel rod and forming machine [11], it is necessary to know the load due to forming forces. The distribution of the load of the tools is illustrated in Fig. 4. The load of the die gradually increases until it stabilizes at around $45 \mathrm{KN}$. The load of the mandrel is initially greater than the steady-state process of about 1.5 KN. This is due to the initial filling of the inner tube profile, and this must be taken into account when designing the mandrel rod. 


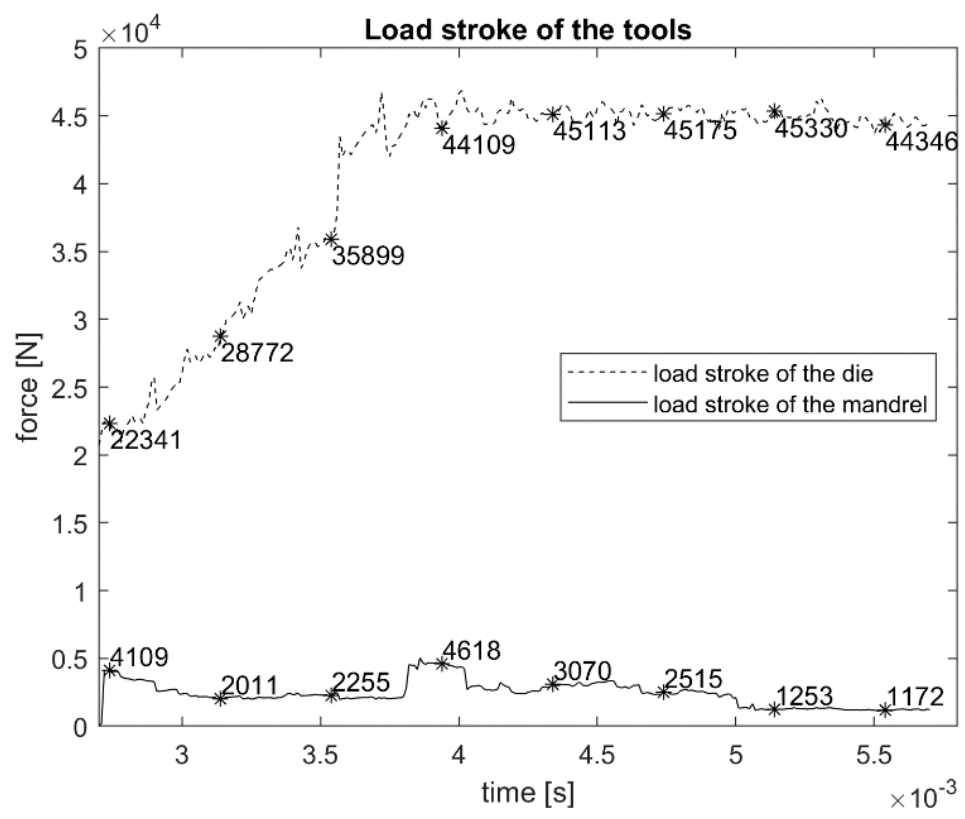

Fig. 4. Distributions of load stroke of the tools

\subsection{Distribution of stresses in the thickness of the tube}

The tube is subjected to strain hardening during of cold forming process. Analysis of the stresses through the thickness allows understanding the forming process and the state of the tube. The distribution of the effective stress through the thickness reveals that the tube is more constrained on surfaces than on in the middle of the tube material. It is clearly visible that the value of the effective stress is close to the mandrel site with a smaller diameter lower. As seen in fig. 5 distributions of stresses with concerning the angle in the tube cross-section. Shear stress is not significant through the thickness of the tube in both areas of mandrel diameter. Moreover, the maximum normal stress is more concentrated on the outer surface than on the inner surface. In the area of mandrel larger diameter is observed the slightly negative value of maximum normal stress (fig. 6,7.).

Finally, the longitudinal stress is concerned, the tube is in compression stress on its inner surface and tensile stress on its outer one. Based on compression stresses on the inner surface of the tube it is possible to use mandrel with ribs and fill it so that it was made the inner fined tube. The forming process should be designed that the compression stress on the inner surfaces should as large as possible due to the reliable filling of the ribs of the mandrel, but the maximum tensile stress must not exceed the strength of the material to be formed. To avoid fracture occurring at the die exit, the drawing stress applied to the drawn section at the die exit must remain within a safety margin below the ultimate tensile stress of the drawn material. The axial stress in the drawn tube is, therefore, the main limitation for drawing as shown by [12].
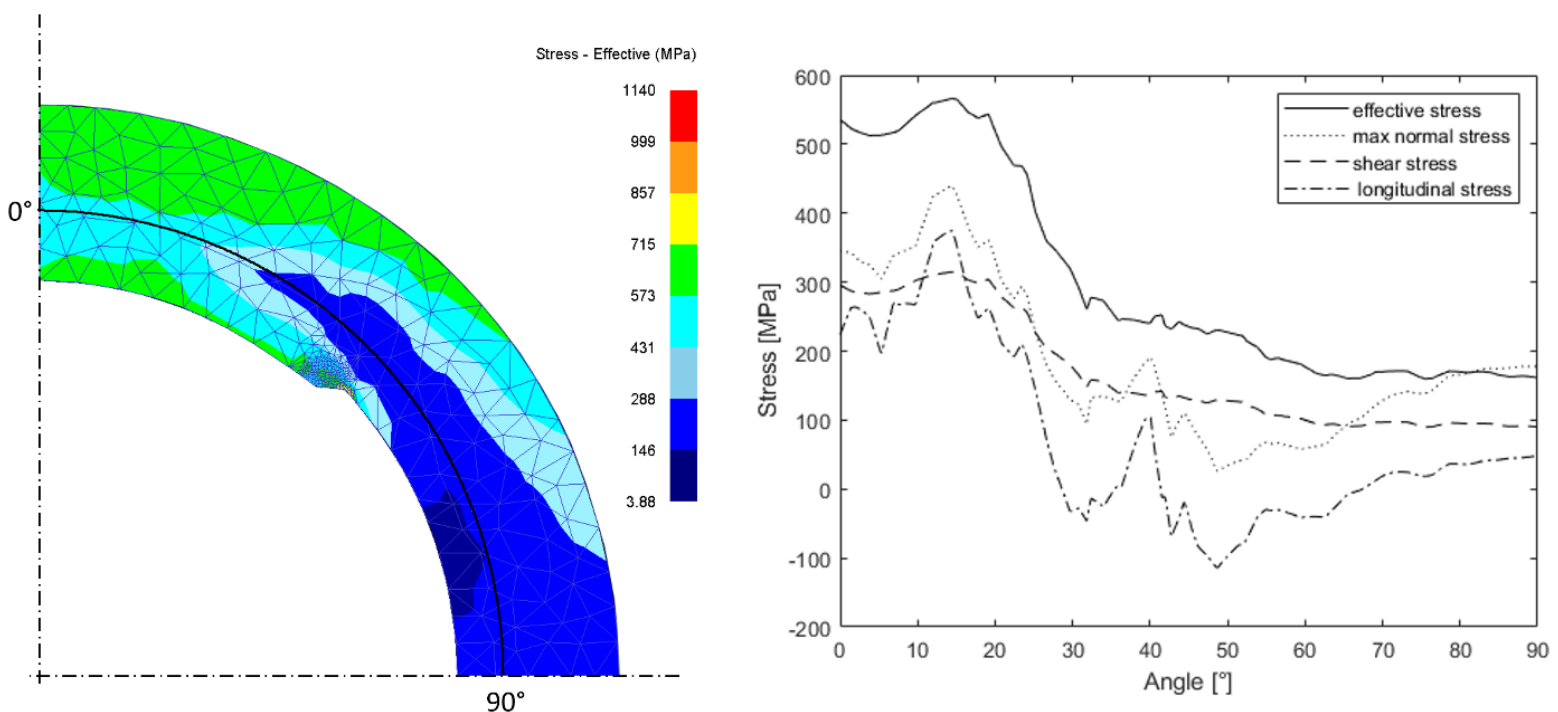

Fig. 5. Distributions of stresses with concerning the angle in the tube cross-section 

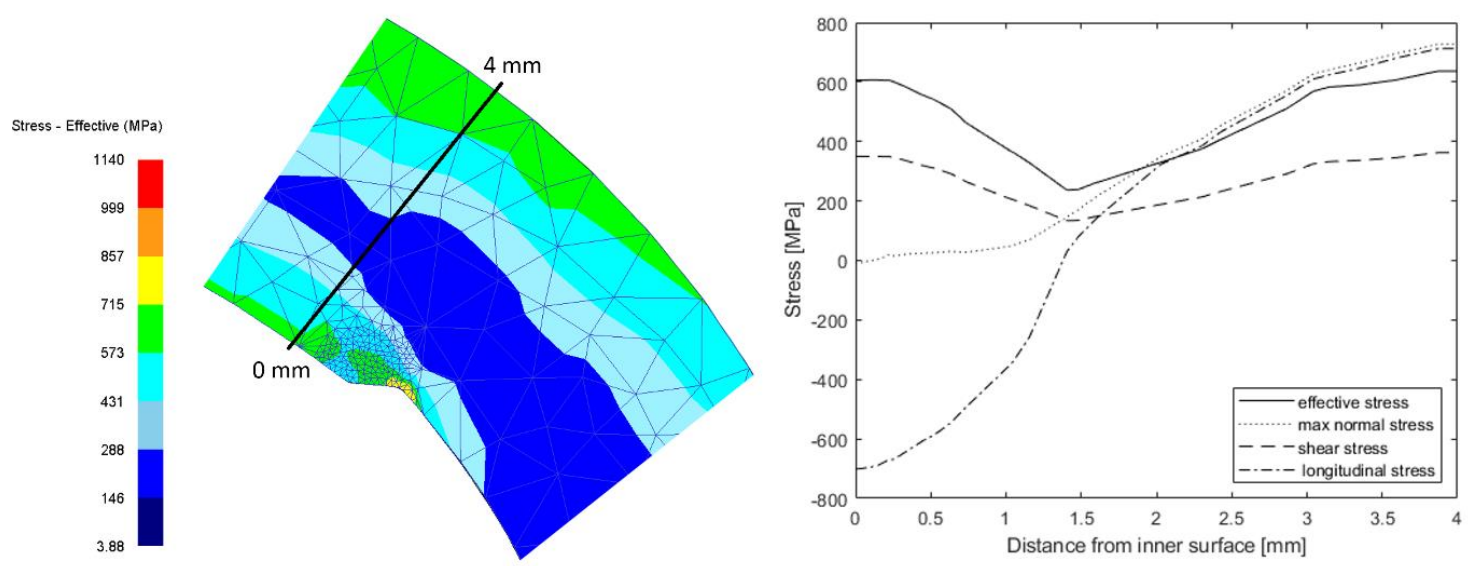

Fig. 6. Distribution of stresses in the thickness for tube cross-section
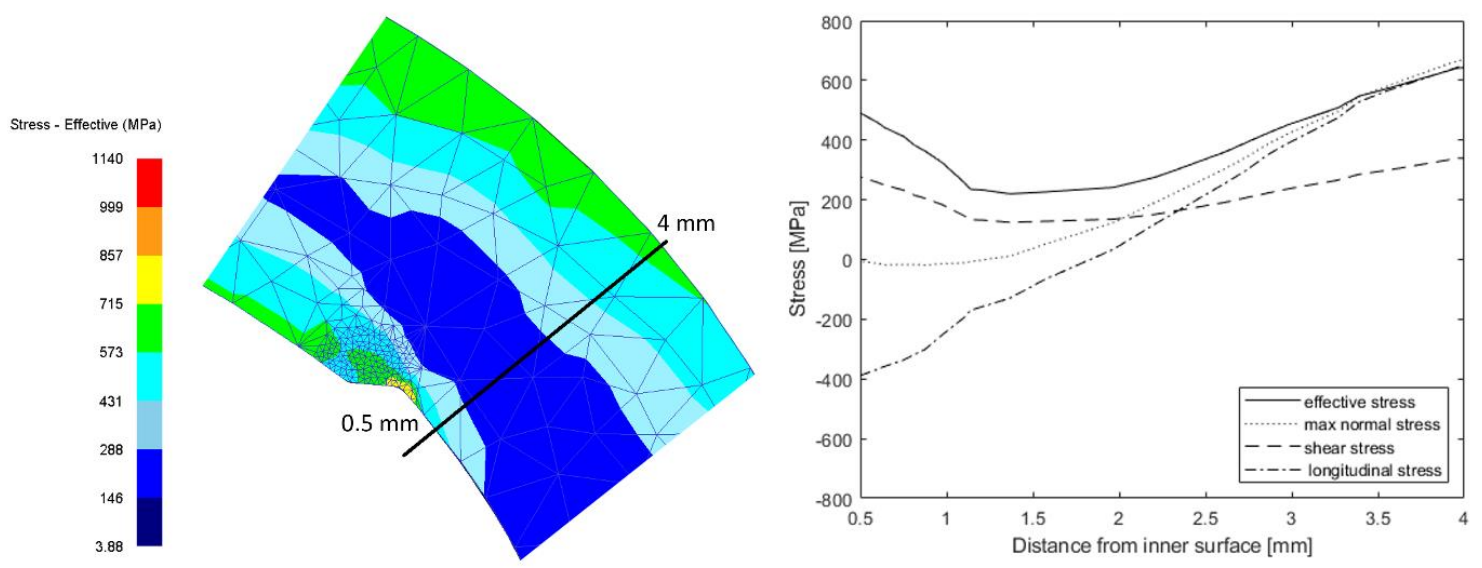

Fig. 7. Distribution of stresses in the thickness for tube cross-section

\section{Conclusion}

This present paper describes the methodology of using DEFORM 3D and numerical Finite Element Simulation of the cold drawing process of inner fined tubes. When designing a simulation model, it is necessary to know the initial properties and initialization boundary conditions. A thorough analysis of the problem and design conditions helps to build a simulation model whose result corresponds to a real problem.

As can be seen from the results of the simulation, when designing tool geometry and process conditions, emphasis must be placed on the correct distribution of stresses along the cross-section of the tube so as to achieve the highest possible compressive stresses on the inner surface of the tube, while not exceeding the maximum possible tensile stresses on the outside of the tube. The compressive stress is important to proper filling the mandrel ribs, vice versa tensile stress is negative due to material failure and cracks.

Besides, the forming tools are loaded by forces that contribute to their wear and shorten the service life. The simulation model described in the article only includes the result of the total forces acting on the forming tools. However, modern numerical methods make it possible to summarize a simulation model of tool wear and tool life, which is, more demanding in terms of hardware performance and computing time.

\section{Acknowledgments}

The article was written with the support of the Project of VEGA grant agency of the Ministry of Education, Science, Research and Sport of the Slovak Republic and the Slovak Academy of Sciences, no. 1/0122/16: "Research of deformation processes using spatial reconstruction of microstructure and shape of formed parts".

This work was supported by the Slovak Research and Development Agency under the Contract no. APVV-15-0319“" Research of technological process of forming at production of tubes with contoured internal surface". 


\section{References}

[1] Yoshida, K. \& Furuya, H. (2004). Mandrel drawing and plug drawing of shape-memory-alloy fine tubes used in catheters and stents J. Mater. Process. Technol. 153-154 145-50

[2] Gusel, L. \& Rudolf, R. (2015). Shear stress distribution analysis in cold formed material Procedia Engineering vol 100 pp 41-5

[3] Boutenel, F.; Delhomme, M.; Velay, V. \& Boman, R. (2018). Finite element modelling of cold drawing for highprecision tubes Comptes Rendus - Mec. 346 665-77

[4] Neves, F. O.; Button, S. T.; Caminaga, C. \& Gentile, F. C. (2005). Numerical and experimental analysis of tube drawing with fixed plug J. Brazilian Soc. Mech. Sci. Eng. 27 426-31

[5] Zhang, L.; Xu, W.; Long, J. \& Lei, Z. (2015). Surface roughening analysis of cold drawn tube based on macro-micro coupling finite element method J. Mater. Process. Technol. 224 189-99

[6] Bella, P.; Buček, P.; Ridzoň, M.; Mojžiš, M. \& Parilák, L. (2017). Numerical simulation of multi-rifled tube drawing - finding proper feedstock dimensions and tool geometry IOP Conf. Ser. Mater. Sci. Eng. 17912008

[7] Bella, P.; Durcik, R.; Ridzon, M. \& Parilak, L. (2018). Numerical simulation of cold drawing of steel tubes with straight internal rifling Procedia Manuf. 15 320-6

[8] Zahálka, M. (2018). Stability of the brass cups forming process Annals of DAAAM and Proceedings of the International DAAAM Symposium vol 29 (Danube Adria Association for Automation and Manufacturing, DAAAM) pp 0435-9

[9] Holmquist, T. \& Johnson, R. (1991). Determination of constants and comparison for various constitutive models J. Phys. 4 853-60

[10] Necpal, M.; Martinkovič, M. \& Václav, Š. (2018). Determination of the Coefficient of Friction Under Cold Tube Drawing Using FEM Simulation and Drawing Force Measurement Res. Pap. Fac. Mater. Sci. Technol. Slovak Univ. Technol. 26 29-34

[11] Chval, Z.; Raz, K. \& Cechura, M. (2015). Analysis of stress distribution in the forging press Annals of DAAAM and Proceedings of the International DAAAM Symposium

[12] Béland, J-F.; Fafard, M.; Rahem, A.; D’Amours, G. \& Côté, T. (2011). Optimization on the cold drawing process of 6063 aluminium tubes Appl. Math. Model. 35 5302-13 